2011s-30

\title{
Bargaining with Linked Disagreement Points
}

\author{
Justin Leroux, Walid Marrouch
}

\begin{tabular}{c}
\hline Série Scientifique \\
Scientific Series
\end{tabular}

\section{Montréal \\ Février 2011}

(Mis à jour le 28 septembre 2011; Update on September 28, 2011)

(C) 2011 Justin Leroux, Walid Marrouch. Tous droits réservés. All rights reserved. Reproduction partielle permise avec citation du document source, incluant la notice $($ ).

Short sections may be quoted without explicit permission, if full credit, including $@$ notice, is given to the source.
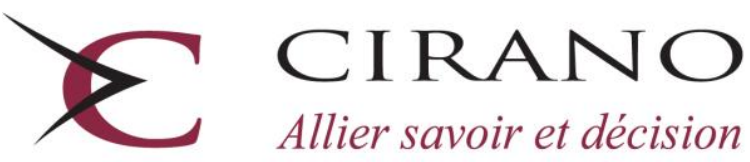

Allier savoir et décision

Centre interuniversitaire de recherche en analyse des organisations 


\section{CIRANO}

Le CIRANO est un organisme sans but lucratif constitué en vertu de la Loi des compagnies du Québec. Le financement de son infrastructure et de ses activités de recherche provient des cotisations de ses organisations-membres, d'une subvention d'infrastructure du Ministère du Développement économique et régional et de la Recherche, de même que des subventions et mandats obtenus par ses équipes de recherche.

CIRANO is a private non-profit organization incorporated under the Québec Companies Act. Its infrastructure and research activities are funded through fees paid by member organizations, an infrastructure grant from the Ministère du Développement économique et régional et de la Recherche, and grants and research mandates obtained by its research teams.

\section{Les partenaires du CIRANO}

Partenaire majeur

Ministère du Développement économique, de l'Innovation et de l'Exportation

\section{Partenaires corporatifs}

Banque de développement du Canada

Banque du Canada

Banque Laurentienne du Canada

Banque Nationale du Canada

Banque Royale du Canada

Banque Scotia

Bell Canada

BMO Groupe financier

Caisse de dépôt et placement du Québec

Fédération des caisses Desjardins du Québec

Financière Sun Life, Québec

Gaz Métro

Hydro-Québec

Industrie Canada

Investissements PSP

Ministère des Finances du Québec

Power Corporation du Canada

Raymond Chabot Grant Thornton

Rio Tinto

State Street Global Advisors

Transat A.T.

Ville de Montréal

\section{Partenaires universitaires}

École Polytechnique de Montréal

HEC Montréal

McGill University

Université Concordia

Université de Montréal

Université de Sherbrooke

Université du Québec

Université du Québec à Montréal

Université Laval

Le CIRANO collabore avec de nombreux centres et chaires de recherche universitaires dont on peut consulter la liste sur son site web.

Les cahiers de la série scientifique (CS) visent à rendre accessibles des résultats de recherche effectuée au CIRANO afin de susciter échanges et commentaires. Ces cahiers sont écrits dans le style des publications scientifiques. Les idées et les opinions émises sont sous l'unique responsabilité des auteurs et ne représentent pas nécessairement les positions du CIRANO ou de ses partenaires.

This paper presents research carried out at CIRANO and aims at encouraging discussion and comment. The observations and viewpoints expressed are the sole responsibility of the authors. They do not necessarily represent positions of CIRANO or its partners. 


\title{
Bargaining with Linked Disagreement Points *
}

\author{
Justin Leroux ${ }^{\dagger}$, Walid Marrouch ${ }^{*}$
}

\begin{abstract}
Résumé / Abstract
Dans un contexte de négociations bilatérales, nous adressons la question de l'inter-connexion des sujets de négociation dans un modèle coopératif à deux-sujets-deux-agents. Les axiomes que nous proposons insistent sur le rôle des points de menace. Une famille de solutions ressort de l'analyse : les solutions monotones à taux nets identiques. Chacune de ces solutions préconise une issue Pareto efficace de sorte que les gains relatifs de chaque agent sont les mêmes pour les deux sujets de négociation. De plus, ces règles récompensent les agents pour des améliorations de leurs pouvoirs de négociation. Nous discutons nos résultats à la lumière des négociations de commerce international et environnementales, qui sont souvent amenées à la table de négociations de manière liée.
\end{abstract}

Mots clés : Négociations Multi-sujets, inter-connexion des sujets, solutions axiomatiques, point de Menace.

In the context of bilateral bargaining, we deal with issue linkage by developing a two-issue-two-player cooperative bargaining model. In contrast to the traditional Nash bargaining literature, the axioms we propose focus on the role of changes in the disagreement points. We characterize a new solution that we call the Linked Disagreement Points (LDP) solution, which explicitly links the players'bargaining powers on each issue. We then weaken our axioms in turn, and a family of bargaining rule stands out: the monotonic equal net ratio solutions. These solutions point to Pareto efficient outcomes such that the relative gains for players are equal across issues and reward the players for improving their bargaining power over each issue. We discuss our results in light of international trade and environmental negotiations, which are often put on the bargaining table in a linked fashion.

Keywords: Multi-issue bargaining, issue linkages, axiomatic solutions, disagreement point.

Codes JEL: C78, Q56.

\footnotetext{
* We are grateful for insightful comments from Walter Bossert, Bernard Sinclair-Desgagné, and participants at the Montreal Resource and Environmental Economics Workshop. This research was made possible in part thanks to funding from SSHRC.

${ }^{\dagger}$ CIRANO and HEC Montréal, 3000 chemin de la Côte-Sainte-Catherine, Montréal, QC H3T 2A7 Montréal, Canada. E-mail: justin.leroux@ @hec.ca. Phone: (+1) 514-340-6864. Fax: (+1) 514-340-6469.

$\$$ CIRANO Lebanese American University, School of Business, Department of Economics and Finance, Beirut, Lebanon, P.O. Box 13-5053 / F-15. New York Office 475 Riverside Drive, Suite 1846 New-York, NY 101150065-USA, Email: walid.marrouch@lau.edu.lb. Phone: (+961) 01786456 Ext:1517. Fax: (+961) 01867098.
} 


\section{INTRODUCTION}

Many bargaining situations involve multiple issues at once. For instance, international trade and environmental negotiations have often been put on the bargaining table in a linked fashion. From Montreal in 1987, through Kyoto (1997) and Cartagena (2003), to Copenhagen in 2009 international environmental agreements were negotiated with the lurking spectre of trade (dis)agreements like the WTO.

Multiple-issue bargaining is a complex process where negotiations often break down and a non-cooperative outcome prevails. The non-cooperative outcomes resulting from disagreement are typically Pareto-inferior. Keeping with our motivating example from international trade, when trade negotiations break down the result is a tariff war leading to substantial welfare losses.

In order to propose Pareto-improving recommendations, we model issue linkages using a cooperative bargaining model with two players and two issues. We consider the linkage between issues by expliciting the relationships between disagreement points and possible Pareto-improving outcomes where the final Pareto efficient outcome is known. As such, we consider bargaining situations where players are negotiating on the sharing of a surplus that is pre-defined at the outset of the negotiation round(s). Stylized facts suggest that countries' negotiation powers over each specific issue (trade or environment) play an important role in shaping the overall outcome of international negotiations because they act as threat points. For instance, trade wars and trade negotiations in the pre-NAFTA context were driven by the parties' disagreement points. In this context, Glenn Harrison and Elisabet Rutström (1991) compute the non-cooperative Nash equilibrium of the trade protection game between the US and Europe and evaluate welfare relative to it. The Nash equilibrium can then serve as a "natural measure of nation's bargaining strength when entering into international trade negotiations, [where] this bargaining strength is based on relative gains and losses in a credible disagreement outcome, which [they] interpret as the disagreement outcome" (p. 421). This bargaining mechanism was also observed within the genetically modified organisms dispute in the years 2003-2006, which pitted the USA, Canada and Argentina on one side and the European Union on the other and was settled in favor of the former group, where negotiation power over trade favored the winners ${ }^{1}$.

The traditional single-issue cooperative bargaining framework describes a feasible bargaining set $X$ and a corresponding disagreement point $d^{X}$. We consider the family of bargaining problems where the feasible set is pre-determined prior to the negotiation round(s) where the role played by the disagreement point is paramount. Therefore, in contrast to the Nash bargaining framework, we normalize the set $X$

\footnotetext{
${ }^{1}$ For further information consult the WTO's dispute database.

http://www.wto.org/english/tratop_e/dispu_e/dispu_subjects_index_e.htm
} 
to be a bargaining 'cake' of size one but allow the disagreement points to vary. (Figure 1) And, when considering simultaneous bargaining over two issues, $X$ and $Y$, we link the two bargaining problems. This linkage is achieved by considering the relative bargaining power of the players over each issue and how they relate to the other.

\section{[FIGURE 1 HERE]}

We propose specific axioms dealing with issue linkages in the presence of nonnormalized disagreement points and normalized bargaining sets. A first axiom, Uniformity, formalizes the linkage between issues by asking that if the agents' relative bargaining powers are identical across issues, this relationship alone should drive the final outcome. As such it specifies to what extent the issues can be treated independently of the other. The second axiom, Invariance, is stronger and states that total payoffs should not be altered by a reallocation of each agent's bargaining power across issues. In other words, by focusing on the combined bargaining powers of the agents' it specifies to what extent the two issues can be treated as a single one.

These two axioms together characterize a family of solutions that are variants to what we call the Linked Disagreement Points (LDP) solution (Theorem 1). Graphically, the LDP solution links the disagreement points of each issues in the mirrored utility space and selects the intersection of that line with the Pareto frontiers of each issue's bargaining set.(Figure 2)

\section{[FIGURE 2 HERE]}

Next, we drop one axiom at a time and explore the type of solutions the other allows. The Invariance axiom appears as the more prescriptive of the two, as it alone leads to a representation result (Theorem 2). By contrast, the Uniformity axiom requires additional properties to arrive at a tractable class of solutions. Therefore, combining Uniformity with other mild axioms leads to a family of solutions, which we call monotonic equal net ratio solutions. These solutions point to Pareto efficient outcomes such that the relative gains for players are equal across issues. Moreover, they are monotonic in the sense that they reward the players for improving their bargaining power over each issue (Theorem 3). The LDP solution belongs to this family of solutions, but not the Nash bargaining solution as it violates Uniformity and thus fails to satisfactorily convey issue linkage. 
The paper unfolds as follows. Section 2 discusses our theoretical contribution in light of the related literature. Section 3 presents the two-issue bilateral bargaining model and the first characterization results. In Section 4, we explore the consequences of weakening the two main axioms in turn. Section 5 concludes.

\section{RELATED LITERATURE}

The literature on bargaining is made up of two strands: one follows a noncooperative approach à la Rubinstein (1982) and the other follows a cooperative or axiomatic approach à la Nash (1950). Our work belongs to the latter. This literature includes a number of attempts at modeling multiple-issue bargaining, which have mostly ignored the importance of changes in the disagreement points and the resulting spillovers between issues. An important general observation about multiple-issue bargaining is that cooperative models have remained silent about the role played by disagreement points, which are typically normalized to zero. Meanwhile, stylized facts discussed earlier suggest that these points are pivotal in negotiations since they acts as threat points ${ }^{2}$. Moreover, the idea of concessions exchange that arises in non-cooperative models is also neglected in those cooperative models.

Most of the theoretical work on multiple-issue bargaining uses two-player models and generalizes existing solutions from single-issue bargaining. This is done by proposing new axioms that generalize or replace the classical ones found in the literature on single-issue bargaining. When agents' preferences are represented by a utility function it is assumed that utilities are additive across issues. Clara Ponsatí and Joel Watson (1997) generalize the Nash solution and the symmetric utilitarian solution. Michael Peters (1986), generalizes Ehud Kalai's (1977) extended family of proportional solutions and John Harsanyi and Reihard Selten's (1972) extended family of non-symmetric Nash solutions. Another approach has been more recently proposed by Mármol and Ponsatí (2008) and uses maximin and leximin preferences when information about preference is limited or when those preferences do not admit a utility representation. This work follows Walter Bossert et al. (1996) and Bossert and Peters (2001) by modeling the global bargaining problem as the Cartesian product of classical (single issue) bargaining problems.

Cooperative bargaining problems invite three possible families of axioms. First, there are axioms that are related to changes in the bargaining set, where the focus is on bargaining situation under variable bargaining trophies. These appear in Peters (1985, 1986), and Ponsatí and Watson (1997) among others, where disagreement points are normalized to zero. Second, there are axioms related to changes in the population on which the literature has been mostly silent since bilateral

\footnotetext{
${ }^{2}$ See Harrison and Rutström (1991).
} 
bargaining is assumed. ${ }^{3}$ Finally, axioms related to changes in the disagreement points have so far not been considered under multiple-issue bargaining. Here, we explore the relevance of these disagreement points in bargaining situations under fixed bargaining trophies. The focus is on the pure contribution of these points to bargaining solutions where the bargaining sets are not allowed to vary during the negotiation rounds, in contrast to the traditional Nash bargaining framework. ${ }^{4}$ More specifically, we propose a number of axioms related to issue linkages when the disagreement points are taken into consideration. This constitutes a main contribution of our model. ${ }^{5}$

Finally, it is very important to draw the distinction between separate and linked Pareto efficiency. Classical axioms that are applied to single-issue problems are based on the idea of separate/local Pareto efficiency, where it is enough for the solution to be on the Pareto frontier of each set to be efficient ${ }^{6}$. In a more general context, Peters (1985) and Ponsatí and Watson (1997) discuss the idea of global efficiency in the context of multi-issue bargaining. They argue that efficiency demands that no possible gains from cooperation are lost, which means that each local solution must belong to Pareto frontier of the sum of the local sets. Given our context where the issue bargaining set is a simplex, any solution located on the Pareto frontiers of both sets, say $X$ and $Y$, maximizes the sum of players' utilities across issues and is thus also globally Pareto efficient.

\section{THE MODEL}

Two agents, $i=1,2$, bargain simultaneously over two issues, $X$ and $Y$. Successful bargaining consists in dividing a total payoff of 1 for each issue between the two agents. Failure to achieve an agreement in both issues results in agents falling back to their disagreement payoffs in both issues; we denote $d_{i}^{X}>0$ (resp. $d_{i}^{Y}$ ) agent $i$ 's payoff on issue $X$ (resp. issue $Y$ ). We impose $d_{1}^{X}+d_{2}^{X} \leq 1$ and $d_{1}^{Y}+d_{2}^{Y} \leq 1$, and denote $\Delta=\left\{z \in \mathbb{R}_{+}^{* 2} \mid 0<z_{1}+z_{2} \leq 1\right\}$. The profile vector $d=\left(d^{X}, d^{Y}\right) \in \Delta \times \Delta$ constitutes a linked bargaining problem. We denote by $\Delta^{2}$ the class of linked bargaining problems.

A linked bargaining solution (or solution), $f: \Delta^{2} \rightarrow \mathbb{R}_{+}^{2} \times \mathbb{R}_{+}^{2}$ maps each bargaining problem to a payoff vector, $f(d)=(x, y) \geq\left(d^{X}, d^{Y}\right)$ such that $x_{1}+x_{2}=1$ and $y_{1}+y_{2}=1$. We interpret $\frac{d_{2}^{X}}{d_{1}^{X}}$ and $\frac{d_{2}^{Y}}{d_{1}^{Y}}$ to be the agents' relative bargaining powers

\footnotetext{
${ }^{3}$ See William Thomson and Terje Lensberg (1989) for single issue models with n-agents.

${ }^{4}$ The envisioned bargaining problems are cases where players know and cannot change the bargaining set. Of course, this does not preclude negotiations in steps toward the final sharing of the pre-fixed set. This point is discussed further in the model section.

${ }^{5}$ Nonetheless, it should be noted that Thomson $(1987,1994)$ and Youngsub Chun and Thomson (1990, 1992) introduce axioms related to the disagreement point but for single-issue bargaining only.

${ }^{6}$ This is the case when both issues are seen separately. The idea of global efficiency only makes sense when linkage is considered.
} 
over issues $X$ and $Y$, respectively. For instance, if $\frac{d_{2}^{X}}{d_{1}^{X}}$ is very small (close to zero) and $\frac{d_{2}^{Y}}{d_{1}^{Y}}$ is large, then player 1 has a strong advantage over issue $X$ but player 2 has a better bargaining power over issue $Y$ (See Figure 3). Lastly, $x_{1}+y_{1}$ and $x_{2}+y_{2}$ are the overall payoffs of agent 1 and agent 2 , respectively.

\section{[FIGURE 3 HERE]}

We introduce two properties that we deem desirable in a solution to a linked bargaining problem. The first axiom stipulates that if the relative bargaining power is the same across issues, the bargaining rule should respect these relative strengths. In other words, if both issues "agree" on the relative strengths of the bargainers, the final outcome should respect this overall relative strength.

AхіOM 1. "Uniformity" $\frac{d_{2}^{X}}{d_{1}^{X}}=\frac{d_{2}^{Y}}{d_{1}^{Y}} \Longrightarrow \frac{x_{2}}{x_{1}}=\frac{y_{2}}{y_{1}}=\frac{d_{2}^{X}}{d_{1}^{X}}$.

Next, we require that the agents' total payoff be independent of how they choose to allocate their bargaining power across issues.

AXIOM 2. "Payoff Invariance with respect to bargaining power reallocation across issues (Invariance)" $\forall d, d^{\prime} \in \Delta^{2}$, such that $d_{1}^{\prime X}+d_{1}^{\prime Y}=d_{1}^{X}+d_{1}^{Y}$ and $d_{2}^{\prime X}+d_{2}^{\prime Y}=$ $d_{2}^{X}+d_{2}^{Y}$,

$$
x_{i}^{\prime}+y_{i}^{\prime}=x_{i}+y_{i}
$$

for $i=1,2$, where $\left(x^{\prime}, y^{\prime}\right)=f\left(d^{\prime}\right)$.

Note that Invariance can be viewed as having both strategic and normative content. From a strategic viewpoint, it ensures that agents cannot manipulate the solution by reallocating their bargaining efforts across issues. I.e., in an ex ante game where agents could revisit their prior investments towards building bargaining power for each issue, none would find an interest to do so. From a normative standpoint, Invariance ensures that the solution be not partial towards one issue over the other. Indeed, it asks that disagreement utility play an equivalent role on each issue, just like agreement utility on each issue has equal weight in each agent's total (agreement) payoff.

These two axioms are not only focused on the role of the disagreement points on each issue, they also convey the notion of linkage, which is the fundamental distinction between the linked bargaining problem and the traditional Nash bargaining problem. We now further illustrate this distinction by showing how linkage would be ignored if one attempted to treat the linked bargaining problem as a single-issue bargaining problem. More specifically, one may be tempted to combine the two issues as follows: the disagreement utility levels of the players would be $D_{1}=d_{1}^{X}+d_{1}^{Y}$ 
and $D_{2}=d_{2}^{X}+d_{2}^{Y}$, respectively, and the size of the cake to be divided would be 2. The reader can easily check that applying, say, the Nash bargaining solution to this (single-issue) problem yields the following total payoffs for each agent:

$$
\left(\begin{array}{c}
x_{1}^{N}+y_{1}^{N} \\
x_{2}^{N}+y_{2}^{N}
\end{array}\right)=\left(\begin{array}{c}
\left(2+D_{1}-D_{2}\right) / 2 \\
\left(2-D_{1}+D_{2}\right) / 2
\end{array}\right) .
$$

The many points in $\Delta^{2}$ giving rise to the above total payoffs are of the form:

$$
\left(\begin{array}{c}
x_{1}^{N} \\
x_{2}^{N} \\
y_{1}^{N} \\
y_{2}^{N}
\end{array}\right)=\left(\begin{array}{c}
\left(1+d_{1}^{X}-d_{2}^{X}\right) / 2-c(d) \\
\left(1-d_{1}^{X}+d_{2}^{X}\right) / 2+c(d) \\
\left(1+d_{1}^{Y}-d_{2}^{Y}\right) / 2+c(d) \\
\left(1-d_{1}^{Y}+d_{2}^{Y}\right) / 2-c(d)
\end{array}\right)
$$

with $|c(d)| \leq \min \left\{\frac{1-d_{1}^{X}-d_{2}^{X}}{2}, \frac{1-d_{1}^{Y}-d_{2}^{Y}}{2}\right\}$ for all $d \in \Delta^{2}$. In particular, taking $c \equiv 0$ amounts to applying the Nash bargaining solution to each issue independently. Hence, the Nash bargaining solution entirely ignores the linkage between both issues. In fact, the Nash bargaining solution, whether applied to the joint (singleissue) problem or to each issue independently, violates Uniformity. ${ }^{7}$

Taken together, the Uniformity and Invariance axioms characterize a family of solutions related to what we call the "Linked Disagreement Points solution" (or LDP solution), which we define as follows:

$$
\left(\begin{array}{l}
x_{1}^{L D P} \\
x_{2}^{L D P} \\
y_{1}^{l D P} \\
y_{2}^{L D P}
\end{array}\right)=\left(\begin{array}{c}
\frac{D_{1}\left(1-d_{2}^{X}\right)+D_{2} d_{1}^{X}}{D_{1}+D_{2}} \\
\frac{D_{1} d_{2}^{X}+D_{2}\left(1-d_{1}^{X}\right)}{D_{1}+D_{2}} \\
\frac{D_{1}\left(1-d_{2}^{Y}\right)+D_{2} d_{1}^{Y}}{D_{1}+D_{2}} \\
\frac{D_{1} d_{2}^{Y}+D_{2}\left(1-d_{1}^{Y}\right)}{D_{1}+D_{2}}
\end{array}\right)
$$

where $D_{1}=d_{1}^{X}+d_{1}^{Y}$ and $D_{2}=d_{2}^{X}+d_{2}^{Y}$. This solution takes its name from the fact that it "links" the disagreement vectors of each issue. This can be seen graphically in Figure 4.

[FIGURE 4 HERE]

\footnotetext{
${ }^{7}$ The reader can easily check that $\frac{x_{2}^{N}}{x_{1}^{N}}=\frac{y_{2}^{N}}{y_{1}^{N}}=\frac{d_{2}^{X}}{d_{1}^{X}}=\frac{d_{2}^{Y}}{d_{1}^{Y}}$ only when $\frac{d_{2}^{X}}{d_{1}^{X}}=\frac{d_{2}^{Y}}{d_{1}^{Y}}=1$.
} 
THEOREM 1. A solution satisfies Uniformity and Invariance if and only if it is a payoff-equivalent variant of the LDP solution:

$$
\left(\begin{array}{l}
x_{1} \\
x_{2} \\
y_{1} \\
y_{2}
\end{array}\right)=\left(\begin{array}{l}
x_{1}^{L D P}-c(d) \\
x_{2}^{L D P}+c(d) \\
y_{1}^{l D P}+c(d) \\
y_{2}^{L D P}-c(d)
\end{array}\right)
$$

with $c: \Delta^{2} \rightarrow R$ such that $c(d)=0$ whenever $\frac{d_{2}^{X}}{d_{1}^{X}}=\frac{d_{2}^{Y}}{d_{1}^{Y}}$.

Proof. The reader can check that such a solution satisfies Uniformity and Invariance. Conversely, consider a solution satisfying both axioms. By Invariance, the total payoff of each agent only depends on each agent's overall bargaining power, $D_{i}=d_{i}^{X}+d_{i}^{Y}$. Now consider an alternative profile, $d^{\prime}$, such that $\frac{d_{2}^{\prime X}}{d_{1}^{\prime X}}=\frac{d_{2}^{\prime Y}}{d_{1}^{\prime Y}}$ with $d_{1}^{\prime X}+d_{1}^{\prime Y}=d_{1}^{X}+d_{1}^{Y}$ and $d_{2}^{\prime X}+d_{2}^{\prime Y}=d_{2}^{X}+d_{2}^{Y}$ (See Figure 5).

[FIGURE 5 HERE]

Note that $\frac{d_{2}^{\prime X}}{d_{1}^{\prime X}}=\frac{d_{2}^{\prime Y}}{d_{1}^{\prime Y}}=\frac{d_{2}^{\prime X}+d_{2}^{\prime Y}}{d_{1}^{\prime X}+d_{1}^{\prime Y}}$. By Uniformity, $x_{1}^{\prime}=y_{1}^{\prime}=\frac{d_{1}^{\prime X}+d_{1}^{\prime Y}}{d_{1}^{\prime X}+d_{1}^{\prime Y}+d_{2}^{\prime X}+d_{2}^{\prime Y}}=$ $\frac{D_{1}}{D_{1}+D_{2}}$ and $x_{2}^{\prime}=y_{2}^{\prime}=\frac{d_{2}^{\prime X}+d_{2}^{\prime Y}}{d_{1}^{\prime X}+d_{1}^{\prime Y}+d_{2}^{\prime X}+d_{2}^{\prime Y}}=\frac{D_{2}}{D_{1}+D_{2}}$. Invariance yields $x_{1}+y_{1}=$ $x_{1}^{\prime}+y_{1}^{\prime}=\frac{2 D_{1}}{D_{1}+D_{2}}=x_{1}^{L D P}+y_{1}^{L D P}$ and $x_{2}+y_{2}=x_{2}^{\prime}+y_{2}^{\prime}=\frac{2 D_{2}}{D_{1}+D_{2}}=x_{2}^{L D P}+y_{2}^{L D P}$. Thus, the solution can be written as in Expression (1) with Uniformity ensuring that $c(d)=0$ whenever $\frac{d_{2}^{X}}{d_{1}^{X}}=\frac{d_{2}^{Y}}{d_{1}^{Y}}$.

\section{RELAXING THE AXIOMS}

We now present what solutions are permitted when dropping the Uniformity and Invariance axioms.

\subsection{Dropping Uniformity}

The role of the Uniformity axiom in the proof of Theorem 1 was to pin down the total payoff that the solution must assign to each agent. Hence, requiring Invariance alone characterizes a class of solutions assigning a total payoff that only depends on each agent's overall bargaining power.

THEOREM 2. A solution satisfies Invariance if and only if it can be written as follows:

$$
\left(\begin{array}{c}
x_{1}+y_{1} \\
x_{2}+y_{2}
\end{array}\right)=\left(\begin{array}{c}
g_{1}\left(D_{1}, D_{2}\right) \\
g_{2}\left(D_{1}, D_{2}\right)
\end{array}\right),
$$

where $D_{i}=d_{i}^{X}+d_{i}^{Y}, i=1,2$.

Proof. This follows directly from the Invariance axiom. 
Many solutions satisfy Invariance, including the well-known Nash bargaining solution. However, because the Invariance axiom is only concerned with aggregate bargaining power, it provides little indication on how to link the bargaining issues, $X$ and $Y$. Quite to the contrary, Invariance dictates to what extent the issues can be treated as a single one. Hence, the Uniformity axiom is a crucial one to explore issue linkage. In what follows, we replace the Invariance axiom by weaker ones and explore the type of solutions afforded by the Uniformity axiom.

\subsection{Dropping Invariance}

The Invariance axiom has strong implications for the nature of the solution. While Invariance is consistent with the additive framework under study, one may wish to explore the possibilities that dropping the Invariance axiom affords. Clearly, the Uniformity axiom alone allows for too many solutions to be of interest, so we shall combine it with other mild axioms.

Keeping with the spirit of impartiality, we argue that a solution should not behave differently across issues. More precisely once bargaining power has been taken into account, via the agents' issue-wise disagreement points, the solution treats both agents and issues symmetrically.

Axiom 3. "Issue neutrality" $\frac{y_{1}-d_{1}^{Y}}{x_{1}-d_{1}^{X}}=\frac{y_{2}-d_{2}^{Y}}{x_{2}-d_{2}^{X}}$

This axiom is an axiom of neutrality vis-a-vis the issues. For example, if $\frac{y_{1}-d_{1}^{Y}}{x_{1}-d_{1}^{X}}>\frac{y_{2}-d_{2}^{Y}}{x_{2}-d_{2}^{X}}$, the solution confers an a priori advantage to player 1 over player 2 in issue $Y$, which can be viewed as undesirable. Therefore, this condition must hold at equality to ensure neutrality with respect to issues once bargaining powers are accounted for.

Next, we ask that a solution be consistent: achieving an agreement in several steps rather than in a single round should not affect the outcome. This axiom requires defining an intermediate linked bargaining problem, where the payoff to be divided in issue $X$ (resp. $Y$ ) is $E^{X} \leq 1$ (resp. $E^{Y} \leq 1$ ). A triple $\left(d ; E^{X}, E^{Y}\right) \in$ $\Delta^{2} \times(0,1]^{2}$ is an intermediate linked bargaining problem (or intermediate problem) if $d_{1}^{X}+d_{2}^{X} \leq E^{X}$ and $d_{1}^{Y}+d_{2}^{Y} \leq E^{Y}$. The domain of a solution is naturally extended to account for intermediate problems.

Axiom 4. "Composition" $f(d)=f\left(f\left(d ; E^{X}, E^{Y}\right)\right)$ for any intermediate problem $\left(d ; E^{X}, E^{Y}\right)$.

The next requirement is one of smoothness, which ensures that the solution be not wildly sensitive to changes in the bargaining powers:

Axiom 5. "Smoothness" $f$ is continuously differentiable in $d$.

Requiring Axioms 3-5 in addition to Uniformity yields a family of bargaining solutions: 
Theorem 3. A solution satisfies Uniformity and Axioms 3-5 if and only if:

$$
\begin{aligned}
& \Delta^{2} \rightarrow \mathbb{R}_{+} \cup\{+\infty\} \\
& d \mapsto \frac{x_{2}-d_{2}^{X}}{x_{1}-d_{1}^{X}}
\end{aligned}
$$

is a continuously differentiable function such that:

i) $\frac{x_{2}-d_{2}^{X}}{x_{1}-d_{1}^{X}}=\frac{d_{2}^{X}}{d_{1}^{X}}$ if $\frac{d_{2}^{X}}{d_{1}^{X}}=\frac{d_{2}^{Y}}{d_{1}^{Y}}$, and

ii) $\frac{x_{2}^{\prime}-d_{2}^{\prime X}}{x_{1}^{\prime}-d_{1}^{\prime X}}=\frac{y_{2}^{\prime}-d_{2}^{\prime Y}}{y_{1}^{\prime}-d_{1}^{\prime Y}}=\frac{x_{2}-d_{2}^{X}}{x_{1}-d_{1}^{X}}$ for all $\left(d^{\prime X}, d^{\prime Y}\right) \in\left(d^{X}, x\right) \times\left(d^{Y}, y\right),{ }^{8}$ where $\left(x^{\prime}, y^{\prime}\right)=$ $f\left(d^{\prime}\right)$.

Proof: The reader can readily check sufficiency, but the proof of necessity, proviso ii), requires several steps. Let $f$ be a bargaining solution satisfying Uniformity and Axioms 3 through 5. Let $d \in \Delta^{2}$ and denote $(x, y)=f(d)$.

Claim 1: For all $d^{\prime}=\left(d^{\prime X}, d^{\prime Y}\right) \in\left[d^{X}, x\right] \times\left[d^{Y}, y\right]{ }^{9}$ the following holds:

(a) $f\left(d^{\prime X}, d^{Y}\right)=(x, y)$;

(b) $f\left(d^{X}, d^{\prime Y}\right)=(x, y)$; and,

(c) $f\left(d^{\prime}\right)=(x, y)$.

Let $d \in \Delta^{2}$ and let $\left(d^{\prime X}, d^{\prime Y}\right) \in\left[d^{X}, x\right] \times\left[d^{Y}, y\right]$. We first prove point (a). By Composition, $y=f^{Y}\left(f\left(d ; d_{1}^{\prime X}+d_{2}^{\prime X}, 1\right)\right)=f^{Y}\left(d ; d_{1}^{\prime X}+d_{2}^{\prime X}, 1\right)$ because the coordinates of the latter term already sum up to 1 . By Issue Neutrality, $\overrightarrow{d^{X} f^{X}\left(d ; d_{1}^{\prime X}+d_{2}^{\prime X}, 1\right)}$ is colinear to $\overrightarrow{d^{Y} f^{Y}\left(d ; d_{1}^{\prime X}+d_{2}^{\prime X}, 1\right)}$ which, together with the fact that $f^{Y}\left(d ; d_{1}^{\prime X}+\right.$ $\left.d_{2}^{\prime X}, 1\right)=y$ and the fact that $\overrightarrow{d^{X} x}$ and $\overrightarrow{d^{Y} y}$ are colinear, implies that $\overrightarrow{d^{X} f^{X}\left(d ; d_{1}^{\prime X}+d_{2}^{\prime X}, 1\right)}$ and $\overrightarrow{d^{X} x}$ are colinear. Lastly, the fact that the coordinates of $f^{X}\left(d ; d_{1}^{\prime X}+d_{2}^{\prime X}, 1\right)$ sum up to $d_{1}^{\prime X}+d_{2}^{\prime X}$ implies that $f^{X}\left(d ; d_{1}^{\prime X}+d_{2}^{\prime X}, 1\right)=d^{\prime X}$. Finally, by the Composition axiom, $f^{X}\left(f\left(d ; d_{1}^{\prime X}+d_{2}^{\prime X}, 1\right)\right)=x$, yielding the result.

Note that, by assumption on $f, x \geq d_{X}^{\prime}$ and $y \geq d_{Y}^{\prime}$. It follows that the rays $\left(d^{X}, x\right)$ and $\left(d^{Y}, y\right)$ are positively sloped, implying $\frac{x_{2}-d_{2}^{X}}{x_{1}-d_{1}^{X}} \in \mathbb{R}_{+} \cup\{+\infty\}$. By Smoothness, $\left(d^{X}, d^{Y}\right) \mapsto \frac{x_{2}-d_{2}^{X}}{x_{1}-d_{1}^{X}}$ is continuously differentiable.

An analogous argument leads to $f\left(d^{X}, d^{\prime Y}\right)=(x, y)$. Finally applying (a) to the latter expression leads to $f\left(d^{\prime X}, d^{\prime Y}\right)=f\left(d^{X}, d^{\prime Y}\right)=(x, y)$, proving point (c).

Claim 2 For all $d^{\prime X} \in\left(d^{X}, x\right) \cap \Delta$ and all $d^{\prime Y} \in\left(d^{Y}, y\right) \cap \Delta$, the following holds:

(a) $f\left(d^{\prime}, d^{Y}\right)=(x, y)$;

(b) $f\left(d^{X}, d^{\prime Y}\right)=(x, y)$; and

(c) $f\left(d^{\prime}\right)=(x, y)$.

${ }^{8}\left(d^{Y}, y\right)$ denotes the line passing through $d^{Y}$ and $y$.

${ }_{9}^{9}\left[d^{Y}, y\right]$ denotes the line segment connecting $d^{Y}$ to $y$. 
We first prove statement (a). Let $d \in \Delta^{2}$. The line $\left(d^{X}, x\right)$ divides $\Delta$ into two convex regions, $\Delta^{+}$and $\Delta^{-}$such that $\Delta^{+} \cap \Delta^{-}=\left(d^{X}, x\right) \cap \Delta$. (See Figure 6)

\section{[FIGURE 6 HERE]}

Let $d^{\prime X} \in\left(d^{X}, x\right) \cap \Delta$ and suppose $d^{\prime X} \notin\left[d^{X}, x\right]$ (the case not covered by Claim 1). We shall show that $f\left(\cdot, d^{Y}\right)$ is stable on each of the subsets $\Delta^{+}$and $\Delta^{-}$. Indeed, suppose there existed $\hat{d}^{X} \in \Delta^{-} \backslash \Delta^{+}$such that $f\left(\hat{d}^{X}, d^{Y}\right) \in \Delta^{+} \backslash \Delta^{-}$. For any $\lambda \in[0,1]$ denote $d^{\lambda, X}=\lambda d^{X}+(1-\lambda) \hat{d}^{X}$. By Continuity of $f$ in $d$, $\lim _{\lambda \rightarrow 1} f^{X}\left(d^{\lambda, X}, d^{Y}\right)=x \in \Delta^{-}$. Yet, by Composition, it must be that $\left[d^{\lambda, X}, f^{X}\left(d^{\lambda, X}, d^{Y}\right)\right] \cap$ $\left[d^{X}, x\right]=\emptyset$ for any $\lambda<1$. Otherwise, there would exist some $\bar{d}^{X} \in\left[d^{\lambda, X}, f^{X}\left(d^{\lambda, X}, d^{Y}\right)\right] \cap$ $\left[d^{X}, x\right]$, for which Claim 1 would imply $f\left(\bar{d}^{X}, d^{Y}\right)=x$ and, by Composition, we would have $f\left(\hat{d}^{X}, d^{Y}\right)=\left(f\left(\bar{d}, d^{Y}\right)=x\right.$, contradicting the fact that $f\left(\hat{d}^{X}, d^{Y}\right) \in$ $\Delta^{+} \backslash \Delta^{-}$. Finally, because $\left[d^{\lambda, X}, f^{X}\left(d^{\lambda, X}, d^{Y}\right)\right] \cap\left[d^{X}, x\right]=\emptyset$ for any $\lambda<1$, the convexity of $\Delta^{-}$implies that $C l\left\{f^{X}\left(d^{\lambda, X}, d^{Y}\right) \mid 0 \leq \lambda<1\right\} \cap\{x\}=\emptyset$, where $C l$ is the closure operator, implying that $\lim _{\lambda \rightarrow 1} f^{X}\left(d^{\lambda, X}, d^{Y}\right) \neq x$, a contradiction.

Statement (b) is proved in a similar fashion as statement (a), and (c) is obtained by combining (a) and (b), as was done for Claim

Theorem 3 provides the general structure of linked bargaining solutions satisfying Uniformity and axioms 3 through 5 . In addition, one may find it desirable that the improvement of an agent's bargaining power in either issue should not hurt her overall payoff:

Aхіом 6. "Monotonicity" For all $d, d^{\prime} \in \Delta^{2}$,

$$
\left\{\begin{array}{l}
d_{i}^{\prime} \geq d_{i} \\
d_{j}^{\prime}=d_{j}
\end{array} \quad \Longrightarrow x_{i}^{\prime}+y_{i}^{\prime} \geq x_{i}+y_{i}\right.
$$

where $\left(x^{\prime}, y^{\prime}\right)=f\left(d^{\prime}\right)$.

In order to state the next Theorem, we define the function $a: d \mapsto \frac{x_{2}-d_{2}^{X}}{x_{1}-d_{1}^{X}}$ on $\Delta^{2} . a(d)$ can be interpreted as the ratio of relative gains of agent 2 over agent 1 on issue $X$ (and, therefore, on issue $Y$ as well).

Corollary 1. A solution satisfies Uniformity and Axioms 3-6 if and only if:

$$
\begin{aligned}
& \frac{\partial a}{\partial d_{1}^{X}} \leq \frac{x_{2}-d_{2}^{X}}{\left(x_{1}-d_{1}^{X}\right) A} \\
& \frac{\partial a}{\partial d_{2}^{X}} \geq-\frac{1}{A} \\
& \frac{\partial a}{\partial d_{1}^{Y}} \leq \frac{x_{2}-d_{2}^{X}}{\left(x_{1}-d_{1}^{X}\right) A} \\
& \frac{\partial a}{\partial d_{2}^{Y}} \geq-\frac{1}{A}
\end{aligned}
$$


where $A=x_{1}+y_{1}-d_{1}^{X}-d_{1}^{Y}$, in addition to the conditions of Theorem 3.

Proof: We show the first inequality. Let $f$ satisfy axioms 1-5. Let $d \in \Delta^{2}$, and $\varepsilon>0$ such that $\left(d_{1}^{X}+\varepsilon, d_{2}^{X}, d_{1}^{Y}, d_{2}^{Y}\right) \in \Delta^{2}$. Denote $\alpha=a\left(d^{X}, d^{Y}\right),\left(x^{\prime}, y^{\prime}\right)=$ $f\left(d_{1}^{X}+\varepsilon, d_{2}^{X}, d_{1}^{Y}, d_{2}^{Y}\right)$ and $\alpha^{\prime}=a\left(d_{1}^{X}+\varepsilon, d_{2}^{X}, d_{1}^{Y}, d_{2}^{Y}\right)$. By definition of $a(\cdot), x_{2}^{\prime}-d_{2}^{X}=$ $\alpha^{\prime}\left(x_{1}^{\prime}-d_{1}^{X}-\varepsilon\right)$ and $x_{2}^{\prime Y}-d_{2}^{Y}=\alpha^{\prime}\left(f_{1}^{Y}-d_{1}^{Y}\right)$. Adding both equalities yields $x_{2}^{\prime}+y_{2}^{\prime}-d_{2}^{X}-d_{2}^{Y}=\alpha^{\prime}\left(x_{1}^{\prime}+y_{1}^{\prime}-d_{1}^{X}-d_{1}^{Y}-\varepsilon\right)$. The same operation applied to the original bargaining problem yields $x_{2}+y_{2}-d_{2}^{X}-d_{2}^{Y}=\alpha\left(x_{1}+y_{1}-d_{1}^{X}-d_{1}^{Y}\right)$. Subtracting the latter equality from the previous one yields $x_{2}^{\prime}+y_{2}^{\prime}-x_{2}-y_{2}=$ $\alpha\left(x_{1}+y_{1}-d_{1}^{X}-d_{1}^{Y}\right)-\alpha^{\prime}\left(x_{1}^{\prime}+y_{1}^{\prime}-d_{1}^{X}-d_{1}^{Y}-\varepsilon\right)$. Using the fact that $x_{1}^{\prime}+y_{1}^{\prime}+x_{2}^{\prime}+y_{2}^{\prime}=$ $x_{1}+y_{1}+x_{2}+y_{2}=2$ leads to:

$$
\begin{aligned}
x_{1}^{\prime}+y_{1}^{\prime}-x_{1}-y_{1}= & \alpha\left(x_{1}+y_{1}-x_{1}^{\prime}-y_{1}^{\prime}\right)+\left(\alpha-\alpha^{\prime}\right)\left(x_{1}^{\prime}+y_{1}^{\prime}\right) \\
& -\left(\alpha-\alpha^{\prime}\right)\left(d_{1}^{X}+d_{1}^{Y}\right)+\alpha^{\prime} \varepsilon \\
\left(1+\alpha^{\prime}\right) \frac{x_{1}^{\prime}+y_{1}^{\prime}-x_{1}-y_{1}}{\varepsilon}= & \alpha^{\prime}+\frac{\left(\alpha-\alpha^{\prime}\right)}{\varepsilon}\left(x_{1}+y_{1}-d_{1}^{X}-d_{1}^{Y}\right) .
\end{aligned}
$$

Taking the limit towards $\varepsilon=0$ leads to:

$$
(1+\alpha) \frac{\partial\left(x_{1}+y_{1}\right)}{\partial d_{1}^{X}}=\alpha-\frac{\partial a}{\partial d_{1}^{X}} \times\left(x_{1}+y_{1}-d_{1}^{X}-d_{1}^{Y}\right) .
$$

It follows from this last expression that imposing monotonicity $\left(\frac{\partial\left(x_{1}^{\prime}+y_{1}^{\prime}\right)}{\partial d_{1}^{X}} \geq 0\right)$ amounts to requiring $\alpha-\frac{\partial a}{\partial d_{1}^{X}}\left(x_{1}+y_{1}-d_{1}^{X}-d_{1}^{Y}\right) \geq 0$, as was to be proven. The other inequalities are proven similarly

Several solutions stand out among the ones satisfying Uniformity and Axioms 3-6. For instance, any rule taking a convex combination of the relative bargaining powers in each issue, such that $a\left(d^{X}, d^{Y}\right)=\lambda \frac{d_{2}^{X}}{d_{1}^{X}}+(1-\lambda) \frac{d_{2}^{Y}}{d_{1}^{Y}}$ for some $\lambda \in[0,1]$, belongs to this class. We call this the class of monotonic equal net ratio solutions (See Figure 7 ).

\section{[FIGURE 7 HERE]}

This class consists of a continuum of solutions of which an extreme case stands out. The single-issue dictatorship solution requires bargaining gains be allocated according to the relative bargaining powers over issue $X$ (i.e., $\frac{d_{2}^{X}}{d_{1}^{X}}$ ) only. In other words, the bargaining power $\frac{d_{2}^{Y}}{d_{1}^{Y}}$ over issue $Y$ does not matter (See Figure 8). 
The LDP solution could be seen as a refinement, where the gains on each issue depend on the absolute bargaining powers of each agents: $a\left(d^{X}, d^{Y}\right)=\frac{d_{2}^{X}+d_{2}^{Y}}{d_{1}^{X}+d_{1}^{Y}}$,

which amounts to defining the convex combination as $\lambda\left(d^{X}, d^{Y}\right)=\frac{d_{1}^{X}}{d_{1}^{X}+d_{1}^{Y}}$. Graphically and as was discussed earlier, this solution links both disagreement points $d^{X}$ and $d^{Y}$, and locates the solution outcome on the Pareto frontier of each bargaining set (see Figure 2). Thus the LDP solution could be seen a balanced compromise solution since it combines the bargaining powers over both issues: it takes the global bargaining power ratio between both players to determine the outcome.

It is noteworthy that the degrees of freedom granted by the class of monotonic equal net ratio solutions is "horizontal", in the sense that linkage is not a question of how strongly the two issues are linked, but a question of how much weight is given to the relative bargaining powers in each issue. In particular, a solution treating both issues separately would not belong to the class. This can be seen with the (single issue) Nash bargaining solution, for instance, which would correspond to $a \equiv 1$ at all profiles, thus violating Uniformity as was demonstrated ealier. In other words, "no linkage" is not a special case of linkage.

\section{CONCLUDING REMARKS}

Stylized facts suggest that in international law, issues pertaining to commerce and environment are usually dealt with in a conflicting manner. This has been a trend since 1972 when the United Nations Environment Program (UNEP) was established. That year was the year of the United Nations' conference on the environment held in Stockholm, and is now seen as a turning point in international environmental awareness. The conflicting nature of international environmental law stems from the fact that trade and environmental concerns carry trade-offs. The GATT (WTO after 1995) is in general against unilateral discriminatory measures, as per Article XX. However, if these measures are required by an international environmental agreement (IEA) then the issue becomes more problematic because simultaneous negotiations are needed. Indeed, the class of monotonic equal net ratio solutions, which takes a convex combination of the relative bargaining powers in each issue, seems to reflect the way simultaneous bilateral bargaining over trade and environment has been taking place. In this example, if environmental measures are not in conflict with WTO's Article XX then a solution in the spirit of the single-issue dictatorship solution requires bargaining gains be allocated according to the relative bargaining powers over the trade issue only (See, e.g. the 1991 GATT tuna case pitting Mexico versus USA, and the 2001 WTO Shrimp case pitting the USA versus Malaysia, Philippines, Pakistan and India). In this case there is precedence of the older treaty, that is the GATT/WTO. Otherwise, a 
convex combination of relative powers over both issues will determine the final outcome as was the case with the Genetically Modified Organisms (GMOs) conflict in 2003 between the USA, Canada, Argentina on one hand and the EU on the other. ${ }^{10}$ During this conflict, an IEA - the Cartagena protocol on bio-safety - was used to challenge WTO rules; in other words, a convex combination of trade and environment negotiation powers shaped the final solution of the conflict. In this case there is precedence for the more precise treaty, that is the Cartagena protocol. Yet, this precedence is not absolute because the older treaty, which is on trade, still has jurisdiction. Moreover, the monotonic equal net ratio solutions may also inform us about the future resolution outcome of the aviation emissions dispute pitting EU versus non-EU countries. Because aviation emissions were recently included into the European Emission Trading Scheme (ETS), non-EU airlines operating international routes will also have to comply with the ETS. In response, non-EU countries are considering retaliatory measures invoking trade sanctions and calling upon the European Court of Justice for a ruling. As in the Cartagena dispute a monotonic equal net ratio solution can be expected given its desirable properties for the bargaining countries. ${ }^{11}$

\footnotetext{
${ }^{10} \mathrm{http} / / /$ www.wto.org/english/tratop_e/dispu_e/cases_e/ds291_e.htm

${ }^{11}$ For more information about the aviation emissions case in the EU ${ }^{-}$see the July 2011 Newsletter of the International Center for Climate Governance.
} 


\section{REFERENCES}

[1] Bossert W, Peters H (2001) Minimax regret and efficient bargaining under uncertainty. Games and Economic Behavior 34: 1-10

[2] Bossert W, Nosal E, Sadanand V (1996) Bargaining under uncertainty and the monotone path solutions. Games and Economic Behavior 14: 173-189

[3] Chun,Y. Thomson,W. (1990) Bargaining with uncertain disagreement points, Econometrica 58: 951-959

[4] Chun,Y. Thomson,W. (1992) Bargaining problems with claims, Mathematical Social Sciences 24: 19-33

[5] Harrison GW, Rutström E (1991) Trade Wars, Trade Negotiations and Applied Game Theory. The Economic Journal 101: 420-435

[6] Harsanyi JC, R. Selten (1972) A Generalized Nash Solution for Two-Person Bargaining Games with Incomplete Information. Management Science 18: 80106

[7] Horstmann IJ, Markusen JR, Robles J (2005) Issue Linking in Trade Negotiations: Ricardo Revisited or No Pain No Gain. Review of International Economics 13: $185-204$

[8] Kalai E (1977) Proportional solutions to bargaining situations: Intertemporal utility comparisons. Econometrica 45: 1623-1630

[9] Kalai E, Smorodinsky M (1975) Other solutions to the Nash bargaining problem. Econometrica 43: 513-518

[10] Luce RD, Raiffa, H (1957) Games and decisions. Wiley, New York

[11] Mármol AM, Ponsatí C (2008) Bargaining over multiple issues with maximin and leximin preferences. Social Choice and Welfare 30: 211-223

[12] Myerson RB (1977) Two-person bargaining problems and comparable utility. Econometrica 45: 1631-1637

[13] Nash JF (1950) The Bargaining Problem. Econometrica 18:155-162

[14] Peters H (1985) A note on additive utility and bargaining. Economics Letters 17: $219-222$

[15] Peters H (1986) Simultaneity of issues and additivity in bargaining. Econometrica 54: 153-169 
[16] Ponsatí C, Watson J (1997) Multiple-issue bargaining and axiomatic solutions. International Journal of Game Theory 26: 501-524

[17] Rubinstein A (1982) Perfect Equilibrium in a Bargaining Model. Econometrica 50: $97-110$

[18] Thomson W (1987) Monotonicity of bargaining solutions with respect to the disagreement point. Journal of Economic Theory 42: 50-58

[19] Thomson W (1994) Cooperative models of bargaining, in: Aumann R, Hart S (eds) The handbook of game theory

[20] Thomson, W., Lensberg, T. (1989) Axiomatic Theory of Bargaining With a Variable Number of Agents. Cambridge University Press. 


\section{FIGURES}

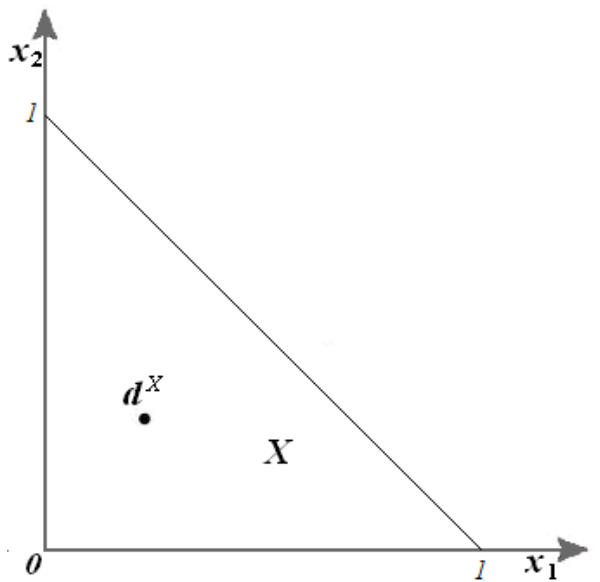

Figure 1. The feasible set $X$ when normalized to unity

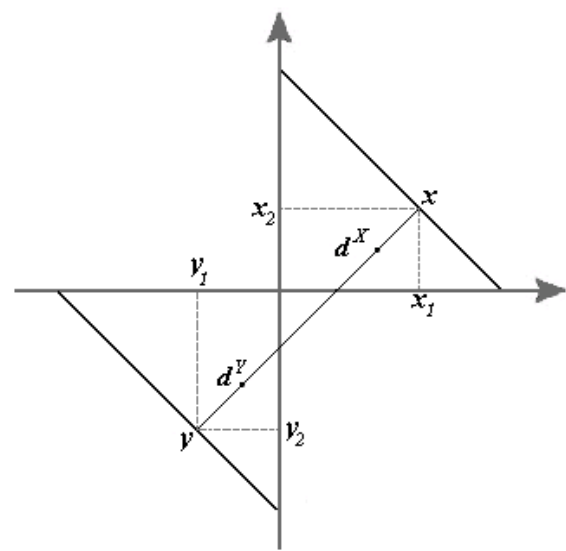

Figure 2. The Linked Disagreement Points Solution 


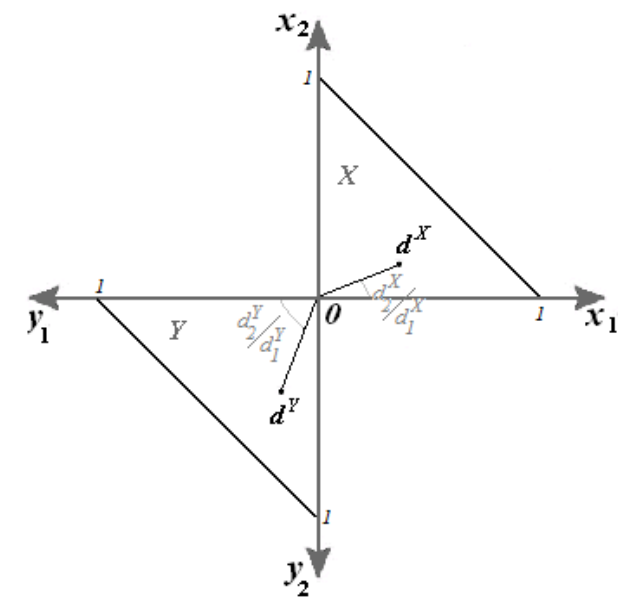

Figure 3. The two-issue bargaining problem

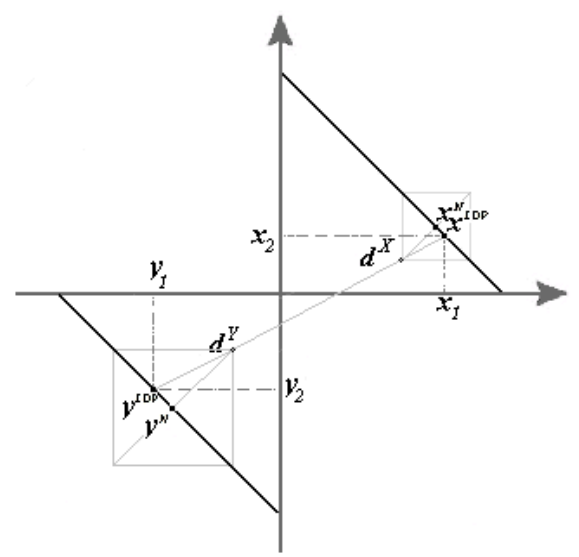

Figure 4. The LDP and Nash solutions 


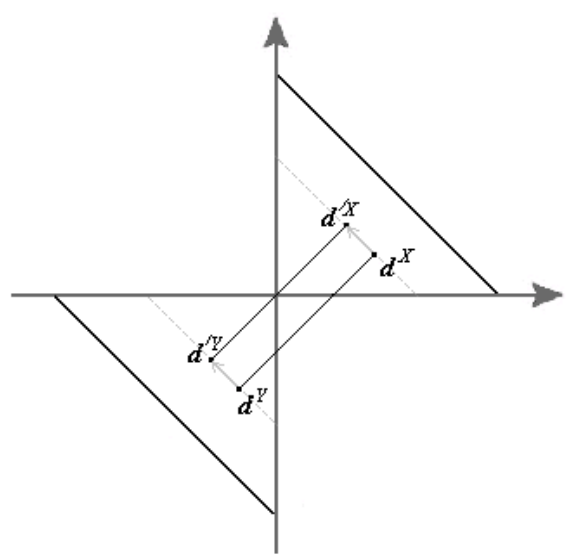

Figure 5.

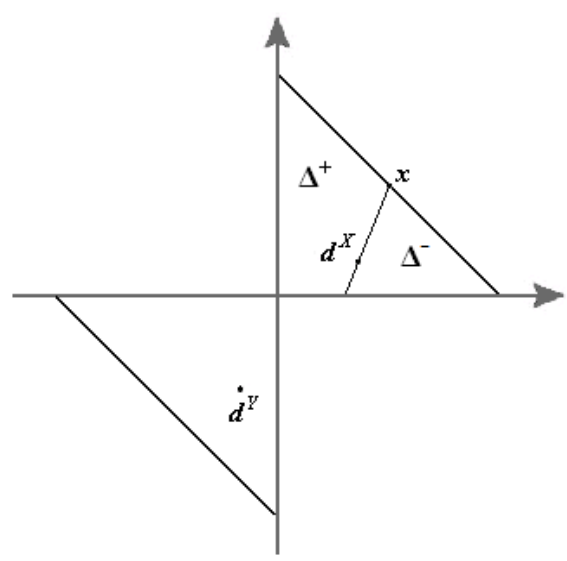

Figure 6 . 


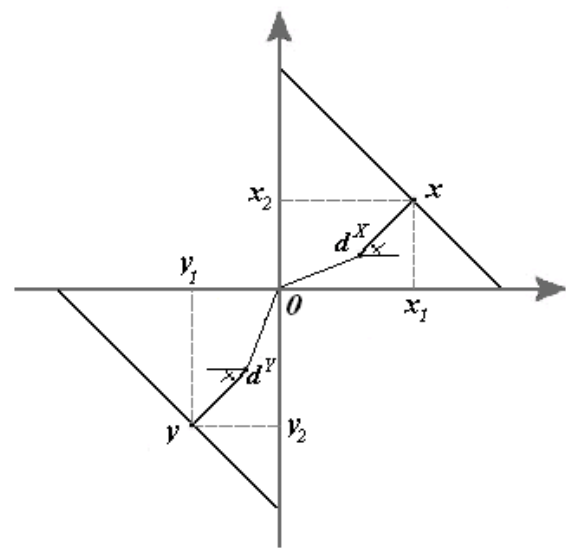

Figure 7. The monotonic equal net ratio solution when $\alpha=1 / 2$.

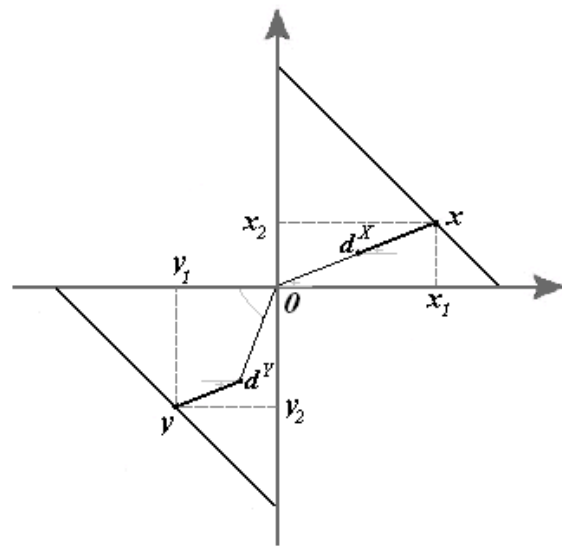

Figure 8. Single-issue dictatorship (issue $X$ ) 